\title{
Anthelmintic activity of Piper sylvaticum Roxb. (family: Piperaceae): In vitro and in silico studies
}

\author{
Arkajyoti Paul ${ }^{1,2^{*}}$ (D, Md. Adnan ${ }^{3}$, Mohuya Majumder ${ }^{1,6}$, Niloy Kar $^{4}$, Muntasir Meem ${ }^{4}$, \\ Mohammed Shahariar Rahman ${ }^{5}$, Akash Kumar Rauniyar ${ }^{7}$, Nishat Rahman ${ }^{1,6}$, Md. Nazim Uddin Chy ${ }^{1,3}$ \\ and Mohammad Shah Hafez Kabir ${ }^{1,3}$
}

\begin{abstract}
Background: The present study was conducted to investigate the anthelmintic activity of methanol extract of Piper sylvaticum stem (MEPSS) in experimental model followed by in silico molecular docking study and ADME/T analysis.

Methods: Anthelmintic activity was determined by an aquarium worm (Tubifex tubifex). Then, molecular docking study was performed to identify compounds having maximum activity against TUBULIN-COLCHICINE enzymes by using Schrödinger-Maestro $\vee 10.1$ docking fitness. Additionally, ADME/T profiles were checked by Swiss ADME Analysis and Molinspiration Cheminformatics software.

Results: A preliminary phytochemical analysis of MEPSS revealed that it contained alkaloids, carbohydrates, flavonoids, tannins, and saponins. MEPSS exhibited a dose-dependent and statistically significant anthelmintic activity on aquarium worm (Tubifex tubifex).The best concentration of MEPSS for anthelmintic activity on Tubifex tubifex compare with reference standard Levamisole $(1 \mathrm{mg} / \mathrm{mL})$ is $11.90 \mathrm{mg} / \mathrm{mL}$. On the other hand, our molecular docking study shows that piperine has the best fitness score of $-6.22 \mathrm{kcal} / \mathrm{mol}$ with TUBULIN-COLCHICINE enzyme among three major compounds of Piper sylvaticum. Moreover, predicted properties of all compounds were in the range to satisfy the Lipinski's rule of five to be recognized as drug like potential.
\end{abstract}

Conclusion: Results of the present study confirmed potential anthelmintic activity of Piper sylvaticum stem extract and all compounds were found to be effective in computer aided drug design models.

Keywords: Piper sylvaticum, Tannins, Anthelmintic, Molecular docking, Toxicity prediction

\section{Background}

Helminths such as roundworm, tapeworm, flukes are soil transmitting parasitic nematodes generally found in the human intestine causing infection to one-third of the humanity and further resulting in great losses of livestock and crops [1]. The last fifty years research has provided few drugs used to cure human helminthiases infection however in long-term use; many parasites are showing resistance to these drugs. This is becoming a foremost problem for environmental and agriculture sector; for example, multiple varieties of drugs containing

\footnotetext{
* Correspondence: arka.bgctub@gmail.com

'Drug Discovery, GUSTO A Research Group, Chittagong 4000, Bangladesh

2Department of Microbiology, Jagannath University, Dhaka 1100, Bangladesh Full list of author information is available at the end of the article
}

macrocyclic lactones, benzimidazoles, praziquantel, and imidathiazoles are used to treat helminthic diseases but one of the studies revealed resistance counter to antihelmintics occurs as soon as their introduction. The reason provided for the decreased response can be either because of heritable changes (genetic or epigenetic) inability of anthelmintic against a population of parasites or reduction in time to which drug treatment applies its effect. Therefore, the use of plant can play a pivotal role in antihelmintic drug target identification $[2,3]$.

The Piperaceae family of genus Piper has 700 species in the form of herbs, shrubs or infrequently trees. Many of the Piper species have high medicinal and commercial importance [4]. Commercially, these species can be found in the spice markets. The therapeutic application 
of Piper species has been successfully reported against several conditions such as antitumor, antimetastatic, cytotoxic, antidepressant, antibacterial, antifungal and antidiabetic [5]. These plant species have good reputation to be used as medicinal agents for a long time in Jamaica for stomach ache and insect repellents. Additionally, roots and fruits of the Piper chaba have been beneficial for asthma, bronchitis, pain, and fever [4]. One of the most important and less investigated Piper Species, Mountain Long Pepper (Piper sylvaticum Roxb.), is a terrestrial, perennial angiosperm widely distributed across South China, India, Bangladesh, and Myanmar. In the Indian subcontinent, the leaves of this plant are used as vegetables and roots as a cure for snake poison [5]. The other research indicates the possible use of $P$. sylvaticum as laxative, anthelmintic, and treatment of bronchitis, and cure remedy for the disease of spleen and liver. The photochemistry of $P$. sylvaticum has been investigated and several physiologically active compounds have been identified such as piperine, piperlonguminine, $\beta$-sitosterol and $\mathrm{N}$-isobutyldeca-trans-2-trans-4-dienamide which maybe possibly responsible for anticancer effects. Pharmacological activities such as antioxidant and hepatoprotective activities have been reported [5-8].

Even though, so far, there is no report demonstrating the anthelmintic activity of the stems of $P$. sylvaticum. Therefore, the present study aims to evaluate the anthelmintic activity of the stems of P. sylvaticum in experimental and computer aided models.

\section{Methods}

Plant material

The stems of Piper sylvaticum (Roxb.) were collected from Kaptai, SitaPahar, Chittagong district, $\left(22^{\circ} 22^{\prime} \mathrm{N} 91^{\circ}\right.$ 48'E), Bangladesh in October 2014 and identified by Dr. Shaikh Bokhtear Uddin, a botanist at the Department of Botany, University of Chittagong (CU), Chittagong 4331, Bangladesh and a voucher specimen with the reference (SUB 3217) has been deposited for future reference in the university herbarium.

\section{Extraction procedure}

The collected stems were washed, cut into small parts, dried in the shade and finally ground into coarse powder. The powdered plant material (about $220 \mathrm{~g}$ ) was taken in a clean, flat-bottomed glass container and soaked in $700 \mathrm{ml}$ of methanol. The particularglass container with the contents was retained for 14 days along with frequent shaking, and the mixture solution was filtered by white sterilized cotton materials accompanied by filter paper (Whatman No.1). Then, the filtrate solution was evaporated in order to yield the methanol extract of P. Sylvaticum (MEPSS: $10 \mathrm{~g}$ ) which was then stored in a refrigerator at $4{ }^{\circ} \mathrm{C}$ until further use.

\section{Drugs and chemicals}

Methanol, hydrochloric acid, and vanillin were purchased from Merck (Darmstadt, Germany). On the other hand, Levamisole collected from ACI Limited, Sonargaon, Bangladesh and catechin from BDH Chemicals Ltd. Poole, UK. All the chemical reagents used in this study were of analytical grade.

\section{Phytochemical screening}

Qualitative phytochemical screening of the MEPSS was carried out to determine the presence of alkaloids, flavonoids, tannins, carbohydrates, and saponins as described previously [9].

\section{Determination of total condensed tannins content}

Total condensed tannins content of MEPSS was estimated by Sun et al. [10, 11]. Briefly, $0.5 \mathrm{ml}$ of extract ( $1 \mathrm{mg} / \mathrm{mL}$ ) was added to $3 \mathrm{ml}$ of $4 \%$ vanillin-methanol solution (v/v) and $1.5 \mathrm{ml}$ of hydrochloric acid and then slightly vortexed. The final mixture was allowed to stand at room temperature for $15 \mathrm{~min}$, and the measurement of the absorbance was taken at $500 \mathrm{~nm}$. The experiment was carried in triple time, and total condensed tannin or proanthocyanidin content was expressed as catechin $(\mathrm{mg} / \mathrm{g})$ by using the equation of the calibration curve $\mathrm{y}$ $=0.5825 \times, R^{2}=0.9277$, where $x$ indicates the absorbance and $y$ refer the catechin equivalent.

\section{In vitro anthelmintic activity}

The Anthelmintic activity of MEPSS was determined according to the previously reported method $[12,13]$. In this study, an aquarium worm (Tubifex tubifex) was used for the test due to its physiological and anatomical similarity with an intestinal worm, i.e., Annelida. The worms were collected from an aquarium shop (Chittagong, Bangladesh) and the average size of worms was used for the experiment from 2 to $2.5 \mathrm{~cm}$ in length. Here, the test was carried in triplicates and randomly divided into five groups:

Group I: used only distil water served as a negative control Group II: used standard drug levamisole $(1 \mathrm{mg} / \mathrm{mL})$ served as positive control

Groups III, IV, and V: served as test groups at three different concentrations $(5,8$ and $10 \mathrm{mg} / \mathrm{mL})$ of MEPSS respectively.

In the present investigation, around 10 to 12 worms were taken in each petri dish in five groups, and $3 \mathrm{~mL}$ of extract solution (MEPSS) of different concentrations were added. Then, the starting time, time of paralysis 
and time of the death of the worms were observed and noted carefully. The anthelmintic activity was evaluated at two different stage 'time of paralysis' and 'time of death' of the worms. The paralysing time was counted when movement of worms could not be observed after shaking vigorously. The time of death was recorded after confirming that the worms moved neither when vigorously shaken nor when dipped in slightly warm water. The best concentration of MEPSS for anthelmintic activity on T. tubifex compare with Standard Levamisole $(1 \mathrm{mg} / \mathrm{mL})$ was measured by linear regression.

\section{In silico molecular docking study}

For molecular docking study, Glide of SchrödingerMaestro (Version 10.1) is used to predict the potent active compound Piper sylvaticum against the active site of TUBULIN-COLCHICINE enzymes where compounds are collected from the literature review [7].

\section{Ligand and protein preparation}

The chemical structures of three major compounds isolated from Piper sylvaticum namely Piperine (PubChem CID: 638024), Piperlonguminine (PubChem CID: 5320621), N-iso butyl deca-trans-2-trans-4-dienamide (PubChem CID: 5318 516) and standard Levamisole (PubChem CID: 26879) were obtained from the PubChem Project database and were structurally plotted in 3 dimensions (3D) using Ligprep 2.5 in Schrödinger Suite, 2015 and their ionization states were generated at pH $7.0 \pm 2.0$ using Epik 2.2 in Schrödinger Suite. In case of the protein preparation, the 3D structure of TUBULIN-COLCHICINE receptor was obtained from the Protein Data Bank (PDB: 1SAO) [14]. Afterward, the structure was prepared and refined using the protein preparation wizard (Schrödinger-Maestro v 10.1) where charges and bond orders were assigned, hydrogens were added to the heavy atoms, selenomethionines were converted to methionine, and all waters portion were removed. On the othe hand, certain thiol and hydroxyl groups were reoriented, and amide groups of asparagines, glutamine, and imidazole ring of histidines, protonation states of histidines, glutamic acidand aspartic acids were optimized at neutral $\mathrm{pH}$. By using force field OPLS_2005, minimization was carried out setting maximum heavy atom RMSD to $0.30 \AA$ [15].

\section{Receptor grid generation}

In Glide, grids were generated keeping the default parameters of van der Waals scaling factor 1.00 and charge cut-off 0.25 subjected to OPLS 2001 force field. A cubic box of specific dimensions centred around the centroid of the active site residues was generated for the receptor. The bounding box was set to $16 \AA \times 16 \AA \times 16 \AA$ and it's essential to identify the active binding site in the target protein.

\section{Glide standard precision (SP) ligand docking}

Flexible ligand docking was performed with Glide of Schrödinger-Maestro (version 10.1) [16, 17] within which penalties were applied to non-cis/trans amide bonds. Glide standard precision docking was performed with these molecules, and hits above $4 \mathrm{kcal} / \mathrm{mol}$ based on docking score with TUBULIN-COLCHICINE enzyme in $\mathrm{XP}$ mode, keeping all docking parameters as default. No bonding constraints were given during docking calculations. Using Monte Carlo random search algorithm, ligand poses were generated for each input molecule, and binding affinity of these molecules to the TUBULIN-COLCHICINE enzyme was predicted regarding Glide docking score. Potential energies of the docked molecules were also predicted with empirical $\mathrm{E}$ model scoring function. Post-docking minimization was performed with OPLS 2005 force field, and one pose per ligand was saved. Strain energies of ligands (bound and free forms) were calculated, and hits with more than $4 \mathrm{kcal} / \mathrm{mol}$ energy difference between the two forms (bound and free forms) received a penalty equal to the quarter of their strain energy difference, which is added to the docking score.

\section{ADME \& toxicity analysis}

As we know molecules of the desired compound must be biologically active in a high amount at the same time, it should be lower in showing toxic activities. It should be easily accessible to the concentration for better therapeutic activity in the human body. To evaluate this pharmacokinetics (i.e. the effect of a remedial compound in the body) of compounds the best way is to separate the different impacts that effect the binding of compounds into the specific active target side. For this purpose, we used Swiss ADME Analysis (http:// www.swissadme.ch/) and Moleinspiration Chemoinformatics software (http://www.molinspiration.com/) to estimate the absorption, distributions metabolism, and excretion of the compounds piperine, piperlonguminine, $\mathrm{N}$-isobutyl deca-trans-2-trans-4-dienamide.

\section{Statistical analysis}

Data were analyzed by SPSS software (statistical package for social science, version 20, IBM Corporation, Armonk, NY, USA) and presented as mean \pm SEM (standard error mean). Here, $P$-values less than $0.05,0.01$ and 0.001 were considered as statistically significant.

\section{Results}

\section{Phytochemical screening}

Phytochemical screening of MEPSS revealed the presence of alkaloids, carbohydrates, flavonoids, tannins, and saponins. 
Total condensed tannins content

The total condensed tannins content of MEPSS was expressed in catechin equivalent (CE), and the content was $55.82 \pm 0.25 \mathrm{mg} \mathrm{CE} / \mathrm{g}$ dried plant extract.

\section{In vitro anthelmintic activity}

The anthelmintic activity of MEPSS was determined on Tubifex tubifex worms. From the result, it can be concluded that the degree of anthelmintic activity was found to be directly proportional to the concentration of the extract ranging from the lowest to highest concentration ( 5 to $10 \mathrm{mg} / \mathrm{mL}$ ). At the concentrations of 5,8 and $10 \mathrm{mg} / \mathrm{mL}$, the MEPSS showed significant paralysis time of $12.86,7.89,4.53 \mathrm{~min}$ and significant death time of $43.95,27.81$ and 21.21 min respectively (Table 1 ) where the standard drug, Levamisole showed a paralysis time of $3.22 \mathrm{~min}$ and death time of $6.06 \mathrm{~min}$. Besides, the best concentration of MEPSS for anthelmintic activity on Tubifex tubifex worms compare with the Standard drug, Levamisole $(1 \mathrm{mg} / \mathrm{ml})$ is $11.90 \mathrm{mg} / \mathrm{ml}$, which is presented in Table 2.

In silico study: Molecular docking for anthelmintic activity In this study, three compounds isolated from Piper sylvaticum stem were selected for molecular docking study and the results shown in Table 3. Molecular docking study showed that Piperine has the best docking score against TUBULIN-COLCHICINE which is $6.22 \mathrm{kcal} / \mathrm{mol}$. The results were compared to that of the standard drug of Levamisole which gives docking score $-6.527 \mathrm{kcal} / \mathrm{mol}$. Interactions between ligands and TUBULIN-COLCHICINE enzyme have been presented in Fig. 1.

\section{ADME \& Toxicity Analysis}

Drug-likeliness activity of the ligand molecule was classified using ADME properties Swiss ADME Analysis and Moleinspiration Chemoinformatics software. The ADME properties (absorption, distribution, metabolism, and elimination) of the piperine, piperlonguminine, and $\mathrm{N}$-isobutyl deca-trans-2-trans-4-dienamide were shown

Table 1 Anthelmintic activity of methanol extract of Piper sylvaticum stem

\begin{tabular}{lll}
\hline Treatment/Dose & $\begin{array}{l}\text { Time is taken for } \\
\text { paralysis }(\mathrm{min})\end{array}$ & $\begin{array}{l}\text { Time is taken for } \\
\text { death }(\mathrm{min})\end{array}$ \\
\hline Control $($ Water $)$ & 0.00 & 0.00 \\
Levamisole $(1 \mathrm{mg} / \mathrm{ml})$ & $3.32 \pm 0.17$ & $6.06 \pm 0.45$ \\
MEPSS $(5 \mathrm{mg} / \mathrm{ml})$ & $12.86 \pm 0.78^{* * *}$ & $43.95 \pm 1.85^{* * *}$ \\
MEPSS $(8 \mathrm{mg} / \mathrm{ml})$ & $7.89 \pm 0.11^{* * *}$ & $27.81 \pm 0.64^{* * *}$ \\
MEPSS $(10 \mathrm{mg} / \mathrm{ml})$ & $4.53 \pm 0.34$ & $21.21 \pm 0.54^{* * *}$ \\
\hline
\end{tabular}

MEPSS denote for methanol extract of Piper sylvaticum stem. Each value in the table is represented as mean $\pm \operatorname{SEM}(n=3)$. ${ }^{* *} P<0.001$ compared with standard drug Levamisole (Dunnett's test)
Table 2 Determinations of the best concentration of methanol extract of Piper sylvaticum stem for anthelmintic activity on Tubifex tubifex worms equivalent with standard drug Levamisole $(1 \mathrm{mg} / \mathrm{ml})$

\begin{tabular}{ll}
\hline Parameter & MEPSS $(\mathrm{mg} / \mathrm{ml})$ \\
\hline Equivalent concentration for time taken for paralysis (A) & 10.73 \\
Equivalent concentration for time taken for death (B) & 13.07 \\
Best concentration of MEPSS $=(\mathrm{A}+\mathrm{B}) / 2$ & 11.90 \\
\hline
\end{tabular}

MEPSS denote for methanol extract of Piper sylvaticum stem

in Table 4. The selected properties are well-known to influence cell permeation, bioavailability and metabolism. Here, predicted properties of all compounds were in the range to satisfy the Lipinski's rule of five to be recognized as drug like potential.

\section{Discussion}

Plant-derived natural products have gained attention as a potential source of new therapeutic agents. The medicinal properties of plants have been investigated due to their potent pharmacological activities, low toxicity, and economic viability. Moreover, most of the clinically active drugs are from natural products which indicate the importance of drugs having natural sources in drug discovery process. So, it is essential to study the medicinal plants so that the discovery of active natural products ingredient can be identified for healing diseases and then the identified active ingredients could be synthesized in the laboratory $[18,19]$. With this view, the plant, $P$. sylvaticum has been investigated for the evaluation of anthelmintic activity using aquarium worm followed by in silico molecular docking study and ADME/T analysis.

Helminths infection is considered to be a significant problem in human and animals that leads to a chronic and devastating disease which ultimately leads to death and also causes drug resistance to other diseases. To prevent infection of helminths, there is a need for studies focusing on natural products such as medicinal plants which give new bioactive compounds having no or fewer side effects, easily available to the peoples of developing countries and more importantly, they have the best compatibility with human physiology than conventional drugs [20-22]. In the present investigation,

Table 3 Docking results of Levamisole (standard drug), piperine, piperlonguminine, and N-isobutyl deca-trans-2-trans-4-dienamide with TUBULIN-COLCHICINE enzyme (PDB: 1SAO) for anthelmintic activity

\begin{tabular}{llll}
\hline Compound name & $\begin{array}{l}\text { Docking Score } \\
\mathrm{kcal} / \mathrm{mol}\end{array}$ & $\begin{array}{c}\text { Glide e model } \\
\mathrm{kcal} / \mathrm{mol}\end{array}$ & $\begin{array}{l}\text { Glide Energy } \\
\mathrm{kcal} / \mathrm{mol}\end{array}$ \\
\hline Levamisole & -6.527 & -39.285 & -28.885 \\
Piperine & -6.22 & -49.492 & -38.113 \\
Piperlonguminine & -5.328 & -43.743 & -32.599 \\
$\begin{array}{l}\text { N-isobutyl deca-trans-2- } \\
\text { trans-4-dienamide }\end{array}$ & -0.337 & -20.961 & -20.594 \\
\hline
\end{tabular}




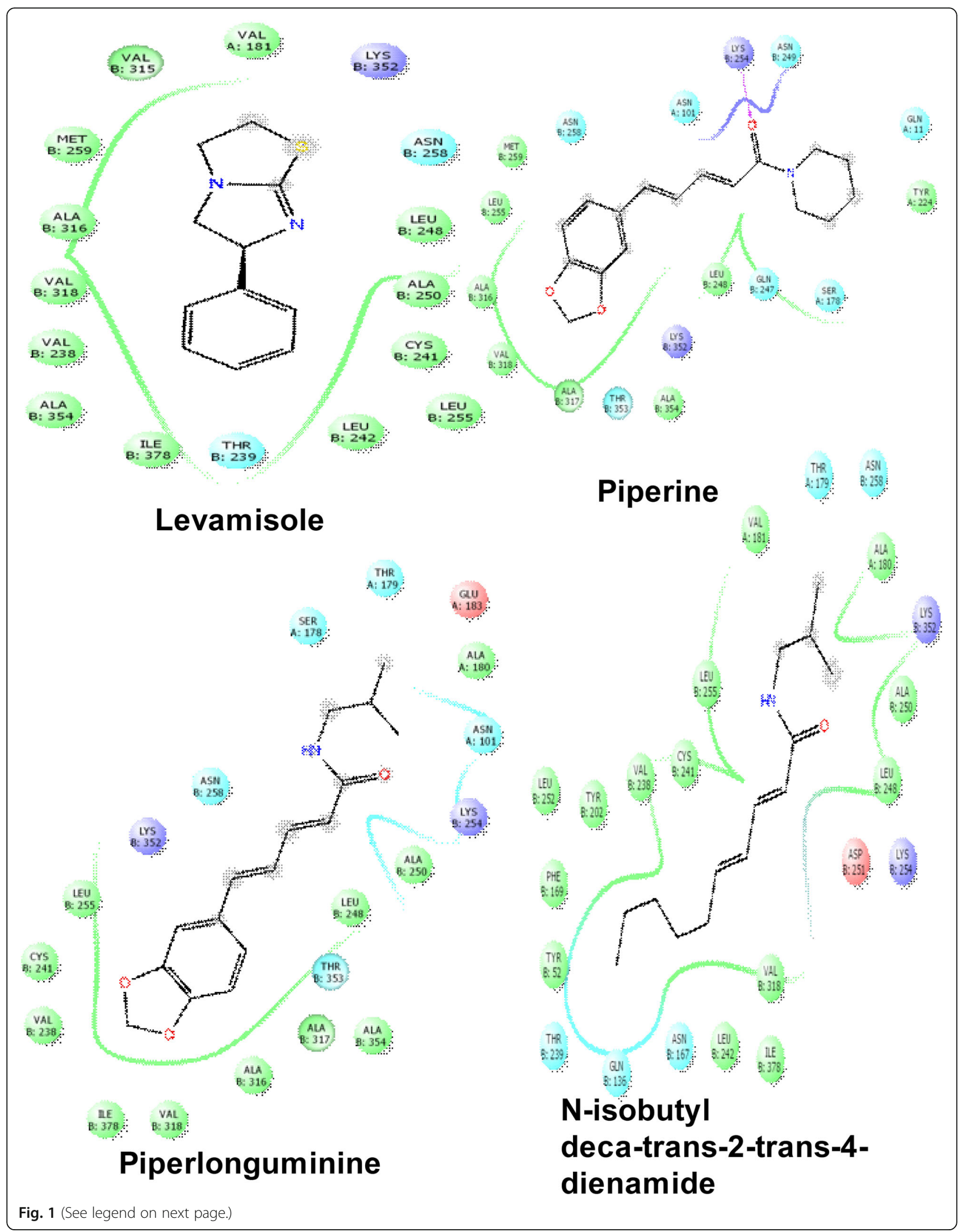


(See figure on previous page.)

Fig. 1 Docking results of Levamisole (standard drug), piperine, piperlonguminine, and N-isobutyl deca-trans-2-trans-4-dienamide with TUBULIN-COLCHICINE enzyme (PDB: 1SAO) for anthelmintic activity. The colors indicate the residue (or species) type: Red-acidic (Asp, Glu), Green-hydrophobic (Ala, Val,lle, Leu, Tyr, Phe, Trp, Met, Cys, Pro), Purple-basic (Hip, Lys, Arg), Blue-polar (Ser, Thr, Gln, Asn, His, Hie, Hid), Light gray-other (Gly, water), Darker gray-metal atoms. Interactions with the protein are marked with lines between ligand atoms and protein residues: Solid pink-H-bonds to the protein backbone, Dotted pink-H-bonds to protein side chains, Green-pi-pi stacking interactions, Orange-pi-cation interactions. Ligand atoms that are exposed to solvent are marked with gray spheres. The protein "pocket" is displayed with a line around the ligand, colored with the color of the nearest protein residue. The gap in the line shows the opening of the pocket

observations were made for the time is taken for paralysis and time is taken for the death of individual worms against the methanol extract and the standard drug, levamisole. The standard drug, levamisole acts as a nicotinic acetylcholine receptor agonist, and it causes persistent stimulation of the parasitic worm muscles, leading to paralysis and ultimately leads to death. Several bioactive phytoconstituents such as alkaloids, tannins, saponins, and flavonoids were found predominantly during preliminary phytochemical analysis of the methanol extract of $P$. sylvaticum which have been associated with anthelmintic properties $[19,22]$. Besides, the plant, $P$. sylvaticum has been already found to be rich in various plant secondary metabolites such as piperine, piperlonguminine, $\beta$-sitosterol, and $\mathrm{N}$-isobutyldeca-trans-2-trans-4-dienamide [7].

Our current study concludes that MEPSS has been found to possess significant anthelmintic potential in a dose-dependent manner. This activity may be due to the presence of bioactive phytoconstituents such as alkaloids, tannins, flavonoids and saponins and also a considerable amount of condensed tannins $(55.82 \pm 0.25 \mathrm{mg}$ $\mathrm{CE} / \mathrm{g}$ ). Some of these phytoconstituents such as alkaloids, tannins, phenols etc. may be responsible for the significant anthelmintic activity [23]. Here, alkaloids can produce paralysis by acting on the central nervous system (CNS) whereas tannins and polyphenols selectively bind to free proteins present in the GI tract (gastrointestinal tract) and eventually cause mortality. On the other hand, the anthelmintic efficacy of saponins is due to its membrane permeabilising property $[19,22]$. The

Table 4 Toxicity and ADME analysis of the phytoconstitiuents isolated from Piper sylvaticum by Swiss ADME Analysis and Molinspiration Cheminformatics software

\begin{tabular}{|c|c|c|c|c|c|}
\hline Compound name & $\begin{array}{l}\text { Molecular } \\
\text { weight }^{\mathrm{a}} \\
(\mathrm{g} / \mathrm{mol})\end{array}$ & $\mathrm{H}_{\text {-donor }}^{\mathrm{b}}$ & H-acceptor ${ }^{c}$ & $\begin{array}{l}\log P \\
\text { value }^{d}\end{array}$ & $\begin{array}{l}\text { Molar } \\
\text { refractivity }\end{array}$ \\
\hline Piperine & 285.34 & 0 & 3 & 3.33 & 85.47 \\
\hline Piperlonguminine & 273.33 & 1 & 3 & 3.30 & 78.77 \\
\hline $\begin{array}{l}\mathrm{N} \text {-isobutyl deca- } \\
\text { trans-2-trans- } \\
\text { 4-dienamide }\end{array}$ & 223.35 & 1 & 1 & 4.26 & 71.47 \\
\hline
\end{tabular}

${ }^{a}$ Molecular weight accepted range $<500$

${ }^{\mathrm{b}}$ Hydrogen bond donor acceptable range $\leq 5$

${ }^{c}$ Hydrogen bond acceptor acceptable range $\leq 10$

${ }^{\mathrm{d}}$ High lipophilicity (expressed as LogP, Acceptable range $<5$ )

e Molar refractivity should be between 40 and 130 anthelmintic activity of the MEPSS may be due to a single compound or combined effect of these phytochemicals.

We have also evaluated the molecular docking of some compounds to demonstrate the collaboration between compounds and protein at the molecular level, which enables us to portray the conduct of molecule of those compounds in the coupling site of targeted proteins and to illustrate the biochemical process of the anthelminthic activity. From the result (as shown in Table 3), it is concluded that piperine $(-6.22 \mathrm{kcal} / \mathrm{mol})$ and piperlonguminine $(-5.32 \mathrm{kcal} / \mathrm{mol})$ showed the significant docking scores which were comparable to those of the reference drug, Levamisole $(-6.52 \mathrm{kcal} / \mathrm{mol})$. The docking score of Piperine is relatively near about the docking score of standard drugs, Levamisole. From the result of docking study, it is clear that these compounds especially piperine can be a good candidate for new anthelmintic agent.

During the ADME analysis of compounds, we have noticed in Table 4 that three compounds show molecular weight less than $500 \mathrm{~g} / \mathrm{mol}$, Hydrogen bond donor activity is less than 5, Hydrogen bond acceptor accepting activity is less than 10 , high lipophilicity $(\log \mathrm{P})$ is less than 5, molar refractivity are between 40 and 130. From the results of ADME and Toxicity analysis, it can be concluded that all compounds were in the range to satisfy the Lipinski's rule of five to be recognized as drug like potential in terms of better pharmacokinetics properties with less toxic effects.

\section{Conclusion}

From above discussion we can assume that this plant can play a prominent role for anthelmintic activity. As it has been accepted in following three experiments, we can suggest Piper sylvaticum for further research to amend the activity of anthelmintic for better effect.

\section{Abbreviations}

MEPSS: Methanol extract of Piper sylvaticum stem; mg: milligram; ml: millilitre; RMSD: Root-mean-square deviation; SEM: Standard error mean

\section{Acknowledgments}

We are greatly thankful to the managing committee of the Department of Pharmacy, International Islamic University Chittagong, Bangladesh for providing all the laboratory facilities and support to complete the research work. Special thanks to A.T.M. Mostafa Kamal, Assistant Professor, Department of Pharmacy, International Islamic University Chittagong for his kind help to complete the study. 


\section{Authors' contributions}

MA and MNUC collected, dried and prepared the extract. MNUC, AP, MM ${ }^{1,6}$ and MSHK conceived and designed the study; MA, MM ${ }^{4}, M S R$, and NK performed the anthelmintic experiment; MNUC, AP, MM ${ }^{1,6}$, and AKR, have analyzed the data and wrote the manuscript. Best concentration calculation for anthelmintic effect was given by MSHK. AP, NR, and MNUC did the molecular docking study and $\mathrm{ADME} / \mathrm{T}$ analysis. All authors read and approved the final manuscript.

\section{Ethics approval and consent to participate}

Not applicable.

\section{Competing interests}

The authors declare that they have no competing interests.

\section{Author details}

'Drug Discovery, GUSTO A Research Group, Chittagong 4000, Bangladesh. 2Department of Microbiology, Jagannath University, Dhaka 1100, Bangladesh. ${ }^{3}$ Department of Pharmacy, International Islamic University Chittagong, Chittagong 4318, Bangladesh. ${ }^{4}$ Department of Pharmacy, East West University, Dhaka 1212, Bangladesh. ${ }^{5}$ Department of Pharmacy, University of Science and Technology Chittagong, Chittagong 4202, Bangladesh. ${ }^{6}$ Department of Pharmacy, BGC Trust University Bangladesh, Chittagong 4000, Bangladesh. ${ }^{7}$ Department of information technology, MDP Bioinformatics, University of Turku, 20500 Turku, Finland.

Received: 3 January 2018 Accepted: 4 June 2018

Published online: 09 July 2018

\section{References}

1. Taylor CM, Wang Q, Rosa BA, Huang SC-C, Powell K, Schedl T, et al. Discovery of anthelmintic drug targets and drugs using chokepoints in nematode metabolic pathways. McKerrow J, editor. PLoS Pathog. Public Library of Science; 2013;9:e1003505

2. Shalaby HA. Anthelmintics resistance; how to overcome it? Iran J Parasitol. Tehran University of Medical Sciences. 2013;8:18-32.

3. Geerts S, Gryseels B. Drug resistance in human helminths: current situation and lessons from livestock. Clin Microbiol Rev American Society for Microbiology (ASM). 2000;13:207-22

4. Virinder S. Parmar, Subhash C. Jain, Kirpal S. Bisht, Rajni Jain, Poonam Taneja, Amitabh Jha, Om D. Tyagi, Ashok K. Prasad, Jesper Wengel, C.E. Olsen, Per M. Boll. Phytochemistry of the genus Piper. Phytochemistry. 1997:46 (4):597673

5. Bezerra DP, Pessoa C, De Moraes MO, Saker-Neto N, Silveira ER, Costa-Lotufo LV. Overview of the therapeutic potential of piplartine (piperlongumine). Eur J Pharm Sci. 2013:48:453-63.

6. Wang Y-H, Morris-Natschke SL, Yang J, Niu H-M, Long C-L, Lee K-H. Anticancer principles from medicinal Piper (胡椒 Hú Jiāo) plants. J Tradit Complement Med. 2014;4(1):8-16.

7. Mahanta PK, Ghanim A, Gopinath KW. Chemical Constituents of Piper sylvaticum (Roxb.) and Piper boehmerifoliurn (Wall). Journal of Pharmaceutical Sciences. 1974;63(7):1160-1161

8. Ved A, Rawat AKS. and Gupta A. Antioxidant and hepatoprotective potential of phenol-rich fraction from piper sylvaticum roxb. roots. Current Topics in Nutraceuticals Research. 2016;14(3): p.207

9. Tiwari P, Kumar B, Kaur M, Kaur G, Kaur H. Phytochemical screening and extraction: A review. Int. Pharm. Sci. 2011:1:98-106

10. Sun JS, Tsuang YH, Chen IJ, Huang WC, Hang YS, Lu F.J. An ultra-weak chemiluminescence study on oxidative stress in rabbits following acute thermal injury. Burns 1998;24:225-231

11. Virinder S. Parmar, Subhash C. Jain, Kirpal S. Bisht, Rajni Jain, Poonam Taneja, Amitabh Jha, Om D. Tyagi, Ashok K. Prasad, Jesper Wengel, C.E. Olsen, Per M. Boll. Phytochemistry of the genus Piper. Phytochemistry. 1997;46(4):597-673

12. Ajaiyeoba EO, Onocha PA, Olarenwaju OT. In vitro anthelmintic properties of Buchholzia coriaceae and Gynandropsis gynandra extracts. Pharm Biol Taylor \& Francis. 2001:39:217-20.

13. Shoibe M, Chy MNU, Alam M, Adnan M, Islam MZ, Nihar SW, Rahman N, Suez E. In Vitro and In Vivo Biological Activities of Cissus adnata (Roxb.). Biomedicines. 2017; 5(4):63. https://doi.org/10.3390/biomedicines5040063.
14. Berman HM, Westbrook J, Feng Z, Gilliland G, Bhat TN, Weissig H, et al. The protein data Bank, 1999-. Int Tables Crystallogr Vol F Crystallogr Biol Macromol Springer; 2006. p. 675-684.

15. Hasanat A, Chowdhury TA, Kabir MSH, Chowdhury MS, Chy MNU, Barua J, Chakrabarty N, Paul A. Antinociceptive Activity of Macaranga denticulata Muell. Arg. (Family: Euphorbiaceae): In Vivo and In Silico Studies. Medicines. 2017; 4(4):88. https://doi.org/10.3390/medicines4040088.

16. Friesner RA, Banks JL, Murphy RB, Halgren TA, Klicic JJ, Mainz DT, et al. Glide: a new approach for rapid, accurate docking and scoring. 1. Method and assessment of docking accuracy. J Med Chem ACS Publications. 2004;47: 1739-49.

17. Halgren TA, Murphy RB, Friesner RA, Beard HS, Frye LL, Pollard WT, et al. Glide: a new approach for rapid, accurate docking and scoring. 2. Enrichment factors in database screening. J Med Chem. ACS Publications. 2004;47:1750-9.

18. Saleh-e-In MM, Sultana N, Hossain MN, Hasan S, Islam MR. Pharmacological effects of the phytochemicals of Anethum sowa L. root extracts. BMC Complement Altern Med. 2016;16:464. https://doi.org/10.1186/s12906-0161438-9.

19. Jamkhande PG, Barde SR. Evaluation of anthelmintic activity and in silico PASS assisted prediction of Cordia dichotoma (Forst.) root extract. Anc Sci Life Medknow Publications. 2014;34:39-43.

20. Sreejith M, Kannappan N, Santhiagu A, Mathew AP. Phytochemical, anti-oxidant and anthelmintic activities of various leaf extracts of Flacourtia sepiaria Roxb. Asian Pac J Trop Biomed Elsevier. 2013:3:947-53.

21. Beech RN, Skuce P, Bartley DJ, Martin RJ, Prichard RK, Gilleard JS. Anthelmintic resistance: markers for resistance, or susceptibility? Parasitology Cambridge University Press. 2011;138:160-74.

22. Maisale AB, Attimarad SL, Haradagatti DS, Karigar A. Anthelmintic activity of fruit pulp of Cordia dichotoma. Int J Res Ayurveda Pharm International Journal of Research in Ayurveda and Pharmacy. 2010;1:597-600.

23. Bate-Smith EC. The phenolic constituents of plants and their taxonomic significance. I. Dicotyledons. Bot J Linn Soc Oxford University Press. 1962:58:95-173.

\section{Submit your manuscript to a SpringerOpen ${ }^{\circ}$ journal and benefit from:}

- Convenient online submission

- Rigorous peer review

- Open access: articles freely available online

- High visibility within the field

Retaining the copyright to your article

Submit your next manuscript at springeropen.com 